\title{
Mental changes in a patient with unrecognized commotio brain after a traffic accident with trauma brain injury
}

\begin{abstract}
Aim: To show a case report of mental health consequances of a felow who survived Trauma brain injury (TBI) with commotio cerebri that was not properly diagnosed in the first emergency medical examination and harm that he and his family suffer because of lack of knowledge and ethics of medical, economic and judical authorities.

Case report: A twenty-six year old male survived a traffic accident that caused TBI. He was misdiagnosed during the emergency examination. Because of that (and other factors) he has not returned to his previous level of functioning. After he treated in the Department of Psychiatry, he went back to his environment a sick leave council interrupted his sick leave, showing mistrust to him and his condition and towards the discharge diagnoses from the Department of Psychiatry. The council sent him to his job without occupational rehabilitation that was recommended. As he could not work in his full capacity, the authorities from his job discharged him on January 2012. When he was on the trial for getting his compensation because of health damages the insurance health expert denied his sufferings and all mental consequences of the commotio cerebri because it was not diagnosed on the first examination in the evening of the accident. So the destiny of this young fellow is very questionable in perspective because of lack of knowledge and ethics of medical staff who are not responsible regarding Hippocratic oath and of industry management who do not take adequate care about their workers who survive traffic accident on the way back to home from their job and who continually suffer because of health particularly mental health consequences.
\end{abstract}

Conclusion: The TBI is an important health public problem and the hospital must establish a perfect managemet in this patients for avoid Mental Changes of Commotio Cerebri.

Keywords: Trauma brain injury; Commotio cerebri; Mental health sequelae; BosniaHerzegovina
Volume I Issue I - 2014

\author{
Mevludin Hasanovic,' Denisa Salihovic, ${ }^{2}$ \\ Amira Kurt ${ }^{3}$ \\ 'Department of Psychiatry, University Clinical Center Tuzla, \\ Bosnia and Herzegovina \\ ${ }^{2}$ Department of Neurology, University Clinical Center Tuzla, \\ Bosnia and Herzegovina \\ ${ }^{3}$ Primary Health Care Centar, Dom zdravlja Tuzla, Bosnia and \\ Herzegovina
}

Correspondence: Mevludin Hasanovic, Department of Psychiatry, University Clinical Center Tuzla, 75000 Tuzla, Bosnia and Herzegovina, Tel 00387-6I-656-608,

Email hameaz@bih.net.ba

Received: April 20, 2014 | Published: May 27, 2014
Abbreviations: TBI, trauma brain injury; GCS, glasgow coma scale; PTA, post-traumatic amnesia; LOC, loss of consciousness; PTSD, post-traumatic stress disorder; GOS, glasgow outcome score; PCS, post-concussion syndrome

\section{Introduction}

The morbidity and severity of brain trauma are both on the top of the list in many kinds of nervous system diseases. According to the American Association of Trauma statistics, there are about 500,000 people admitted to a hospital suffering from craniocerebral trauma every year, 75000-90000 of them die and most of patients are healthy young people who were left with a permanent disability. The consequences of road crashes are various and few studies have dealt with the multidimensionality of outcomes. ${ }^{1}$ The injuries of the head and the neck in car accidents are the most frequent cause of morbidity and mortality in developed and developing countries. ${ }^{2}$ TBI is usually classified based on severity, anatomical features of the injury and the mechanism (the causative forces). ${ }^{3}$ Mechanismrelated classification divides TBI into closed and penetrating head injury. ${ }^{4}$ A closed (nonpenetrating, or blunt) ${ }^{5}$ injury occurs when the brain is not exposed. A penetrating or open head injury occurs when an object pierces the skull and breaches the dura mater, the outermost membrane surrounding the brain. ${ }^{6}$
Brain injuries can be classified into mild, moderate and severe categories. ${ }^{3}$ Based on verbal, motor and eye-opening reactions to stimuli, the Glasgow Coma Scale (GCS), the most commonly used system for classifying TBI severity, grades a person's level of concisousness on a scale of 3-15. It is agreed that a TBI with a GCS of 13 or above is mild, $9-12$ is moderate and 8 or below is severe. ${ }^{7}$ There are other classification systems used also to help determine severity. A current model developed by the ICD 10 as Intracranial injury aplicable to Difuse axonal brain injury. ${ }^{8}$ It also has been proposed to use changes that are visible on neuroimaging, such as swelling, focal lesions or diffuse injury as method of classification. ${ }^{4}$ Grading scales also exist to classify the severity of mild TBI, commonly called concussion these use duration of post-traumatic amnesia (PTA) and loss of consciousness (LOC) and other concussion symptoms. ${ }^{9}$

A variety of signs accompany concussion including somatic (such as headache), cognitive (such as and feeling in a fog), emotional (such as emotional changeability), physical signs (such as loss of consciousness or amnesia), behavioral changes (such as irritability), cognitive impairment (such as slowed reaction times) and/or sleep disturbances. ${ }^{10}$ Symptoms usually resolve within three weeks, though they may persist or complications may occur. ${ }^{11}$ Due to varying definitions and possible underreporting, the rate at which concussion occurs annually is not accurately known but is estimated 
to be more than 6 per 1,000 people. ${ }^{12}$ It is now thought that structural and neuropsychiatric factors may both be responsible for the effects of concussion. ${ }^{13}$ One year after a road accident, the consequences for victims who survived brain injury remain significant: pain frequently persists, impairing daily life for many an elevated rate of chronic post-traumatic stress disorder (PTSD) and a non-negligible impact on affective and occupational life,,$^{14}$ Difficulties in recognizing and diagnosing the commotion of the brain lead to that around $80 \%,{ }^{15}$ to $88.6 \%{ }^{16}$ remains unrecognized. According to some authors, if the symptoms persist longer than 3 months, a diagnosis of postcommotional syndrome is set. ${ }^{17}$

\section{Case report}

A twenty-six year old male survived a traffic accident on 30 October 2008 year about 5p.m. after returning home from his job, as a motorbike rider in a direct collision when he moved forward on the green traffic light and driver of a van started forward through his red light and hit him. After a reconstruction of the accident witnesses, he had fall down on the asphalt two meters from his motorbike after "flying" through the air. Thereby, he attained left side facial injuries, injuries of left limbs, injury of head and he survived a loss of consciousness. He became conscious in the ambulance with which he was transported to emergency center accompanied with no witness of accident. During the examination, the surgeon on duty misdiagnosed him due to he observed his body only and had no data about loss of consciousness that patient survived also he asked only "How do you feel now" and after patient answered that he "feels well", he did not make completed examination of all body and limbs, so he could not see functional impairments of left temporo-mandibular joint, left ear and left eye and he did not see extensive hematomas that developed following morning. Due to that he settled a diagnosis as "Head contusion" only. A day after the accident, parents were horrified when they saw their son after the night, covered with multiple extensive hematomas, feeling very severe pains with no ability to recall the mentioned accident as he did not recall the period of three years back. He complained about double vision and the failure of hearing on the left ear. Gradually, he started to withdraw from others, became impulsive, aggressive, hipped and very nervous. Then he visited neuropsychiatrist who settled a diagnosis of "Commotio cerebri" eleven days after the accident an ophthalmologist settled a diagnosis of "Diplopio posttraumatica" and ENT specialist settled diagnoses "Hypoacusis sin, Post traumatic, Instabilities articulationem TM bill, Post traumatic". Troubles with concentration arose, during the execution of mental activities and also insomnia, fear, emotional tension and excitement arose. He reacted furiously to small, meaningless things. He visited another very experienced neuropsychiatrist after 19 days after accident again, who confirmed the diagnosis of "Commotio cerebri" from the previous neuropsychiatist's examination and suggested sedative, antidepressant and hypnotic. Despite the drug treatment the patient could not recover, he became even worse. He forgot to play harmonica, the musical instrument that he loved to play from his childhood and played excellent before surviving the accident. He forgot all important dates from his life, all birthdays of his close persons. He hangs up with his girlfriend because he lost memories of their common experiences, so he lost affective charge to see her again as before the accident. It happened that he lost his temper quickly and was hostile towards his family. He became impulsive with the tendency to go somewhere and he didn't understand himself at all, thinking that life makes no sense. Despite visiting family physicians, as time passed, his state became worse. He lost trust in doctors and unwillingly attended check-ups. He took the recommended therapy but did not feel well.
Until the day of injury, he was healthy perspective boy. At the age of 8 (during the war in Bosnia and Herzegovina), he moved to Germany with his family. He fit in well learned the German language and functioned well. In 1997, he came back to Bosnia and Herzegovina but not to his birthplace. There, he finished high school and a private music school. Three years before hospitalization to Department of Psychiatry in Tuzla, he returned with his family at his birthplace, got a job and additionally schooled himself for the gain of necessary skills in Czech Republic. Until the day of injury, he worked as a technologic operator on a computer in a private industry of sugar production, he was very prominent and perspective at work that he did. He doesn't smoke, does not consume alcohol or any other psychoactive substance. He was favored in company and gladly hung out with others.

A year after the accident and TBI he was hospitalized in the Department of Psychiatry in University Clinical Center of Tuzla because of a range of somatic and psychological difficulties that were present for the recent year. In the psychological state during the admission to the Department, he was conscious with intact orientation in all directions. On asked questions, he frequently answered with "I don't know". On a math problem (multiplication and division) answers with "I don't know" and became uneasy. On a dictation, he wrote with printed letters only, he presented a low level of basic mood. He appeared with depressive affect with elements of retrograde and anterograde amnesia. He was tense, anxious and impulsive with a low threshold of frustration tolerance. Also he appeared with no hedonism, dejected; with reduced ease-compulsive dynamisms. He denied the existence of perceptive delusions with no an impression that he experiences them. Sometimes he verbalized suicidal thoughts from which he distanced himself rom. He did not appear as heterodestructive.

Laboratory findings were in reference values, except slightly elevated values of triglycerides, cholesterol and LDL cholesterol. Otolaryngologist findings and tonal audiogram has shown the existence of a heavy mixed hearing loss to the left and lighter sensory neural hearing loss to the right. The electroencephalogram finding is on low voltage irregular but within the boundaries of normality. The findings of audio evocated potentials, he was both sides neat. On the nuclear magnetic resonance of the brain, a few lacunar ischemic lesions were found in supratentorial region predominantly in the deep white matter and sub cortically unspecific look of a micro vascular genesis. From psychologist's findings, it is visible that this is a person with visible cognitive disturbances and also signs of psychotic process with depressive nuisance at the sensitive structure of personality. $\mathrm{He}$ showed a low self-respect with the lack of social skills.

During the stay at the Department, the psychological state of the patient was gradually stabilized. In the beginning, he was full of fear and skepticism. With the involvement of SSRI, mood stabilizers and atypical neuroleptic, he becomes calmer with a more adequate mood. We used EMDR sessions for trauma working through and to improve his low self esteem but results were poor because of his blocking up during the therapy also he did not feel comfortable in group psychotherapy sessions because of low capacity to listen to other member in the group. Anxiety reduced, the trust in medical staff was growing up and he gradually gained strength. The patient was treated in a hospital for 21 days because of the limit from the competent health fund with the recommendation for the continuation of outpatient treatment based on monthly visit our Department. It was recommended to continue with occupational rehabilitation and resocialization in some Clinical Center where possible neuropsychological rehabilitation for gaining back occupational competences. 


\section{Epilogue}

After he went back to his hometown in his environment, a sick leave council interrupted his sick leave, showing mistrust to him and his condition and towards the discharge diagnoses from the Department of Psychiatry. In the council there was no any neuropsychiatrist, so they sent him to his job without occupational rehabilitation that was recommended. As he could not work in his full capacity, the authorities from his job discharged him on January 2012. When he was on the trial for getting his compensation because of health damages the insurance health expert denied his sufferings and all mental consequences of the commotio cerebri because it was not diagnosed on the first examination in the evening of the accident. He got compensation only for $16 \%$ of physical injury based on orthopedic expertise. Because of "lack of heavy body injuries" the driver, who hit him with his van was acquitted of charges. After his complaining of loss of job, he got $21 \%$ of his salary for the next two years.

He sued company that fired him out, so he had a psychiatric expertise from a very famous professor of psychiatry, the most competent in the field in the region whose expertise defended the patients right for compensation after five years of accident when it is obvious that patient did not recover as it was expected but on the trial this expertise was not accepted. So the destiny of this young fellow is very questionable in perspective because of lack of knowledge and ethics of medical staff who are not responsible regarding Hippocratic oath and of industry management who do not take adequate care about their workers who survive traffic accident on the way back to home from their job and who continually suffer because of health particularly mental health consequences.

Also system of trials for getting compensation in such situations do not use expertise of highly recognized experts in the field but use the expertise of health experts who work for insurance companies and who put the interests of company above the interest of individual survivors. This is possible in the country as Bosnia and Herzegovina, which is in transitional status after 1992-1995 war because of lack of regulations and ethics, which is part of instable political, economic, social and ethical postwar atmosphere.

\section{Discussion}

After the war in Bosnia-Herzegovina, mental illness is very prevalent. ${ }^{18,19}$ With little knowledge about mental health, the stigma of mental illness is still pervasive in many communities. ${ }^{20}$ After TBI the most important is to begin emergency treatment within the socalled "golden hour" following the injury. Persons with moderate to severe injuries are likely to receive treatment in an intensive care unit followed by a neurosurgical ward ward. Treatment depends on the recovery stage of the patient. In the acute stage the primary aim of the medical staff is to stabilize the patient and focus on preventing further injury because little can be done to reverse the initial damage caused by trauma. Rehabilitation is the main treatment for the subacute and chronic stages of recovery. International clinicl guidelines have been proposed with the aim of guiding decisions in TBI treatment, as defined by an authoritative examination of current evidence. ${ }^{4}$

The prognosis after TBI can be established by use of Glasgow Outcome Score (GOS), the scale that divide patients with TBI into groups that allow standardised descriptions of the objective degree of recovery. The GOS applied to patients with TBIs allowing the objective assessment of their recovery in five categories. This allows a prediction of the long-term course of rehabilitation to return to work and everyday life. Despite lack of knowledge among responsible phisicians in Bosnia and Herzegovina about long term consequances after TBIs with commotio cerebri there are researchs which shows new understanding and severity of conequances for survivors for their mental and psychical health 1,2,4,14

The study on 886 injured road-accident victims, aged $\geq 16$ years and living in the Rhone administrative Département, France (taken from the ESPARR Cohort) showed that at one year post-accident, $45 \%$ of the mild-to-moderate injury group versus only $20 \%$ of severely injured subjects reported full recovery of health $(\mathrm{p}<0.001) .20 \%$ of the cohort, as a whole, reported permanent pain. More than half of the severely injured subjects reported that the accidenthad had an impact on the everyday life of their family this was twice as many as in the mild-to-moderate injury group (55\% vs. $22 \%$ ). Most of the severely injured reported impact on leisure, projects and emotional life $20 \%$ reported relational difficulties in the couple, $16 \%$ reported impaired sexual life and the rate of separation was significantly higher than in the mild-to-moderate injury group ( $5 \%$ vs. $1 \%$; $<0.001)$. Mean time off work was significantly longer in the severe injury group: $245 \pm 158$ days vs. $75 \pm 104$ days $(\mathrm{p}<0.001)$ and $32 \%$ of the severe injury group $(\mathrm{p}<0.001)$ who had stopped work had not returned at 1 year, compared to $5 \%$ of the mild-to-moderate injury group ${ }^{14}$.

The same study population were compared using the World Health Organization Quality of Life Assessment (WHOQOLBREF, a standard instrument of quality of life, assessing physical health, psychological health, social relationships, and environment). The resuts showed that 317 of the 616 subjects $(60.1 \%)$ were men. Five victim groups were identified in terms of consequences at one year: one group (206 subjects, 33.4\%) with few problems, one with essentially physical sequelae, one with problems that were essentially both physical and social and 2 groups with a wider range of problems (one including psychological problems but fewer environmental problems the last one reported negative physical, psychological, social and environmental impact notably, all had post-concussion syndrome $\{\mathrm{PCS}\})$. There were significant differences between groups in terms of family status, injury severity and certain types of injury (thorax, spine, lower limbs). Comparison on the WHOQOL-BREF confirmed that groups reporting more adverse outcomes had a lower quality of life ${ }^{1}$. In our reported case, the surgen on duty misdiagnosed TBI and commotio cerebri, he did not applied GOS, so he did not begin emergency treatment within the "golden hour" also he prevented this young man to pass through objective assesment of his recovery and left him out of the long-term course of rehabilitation to return to work and everyday life.

To ensure that patients with trauma and sequel associated with TBIs during road accidents are able to return to previous levels of functioning, it is necessary to make careful observation and taking history from witnesses of an accident, besides auto anamnesis from the injured person, because this individual cannot say anything about accident because of retrograde amnesia, congrade amnesia and anterograde amnesia. If the diagnosis is not as necessary, the problem of regular treatment and follow up of every patient with commotio cerebri may be risky for the patients' long term perspective. Many patients who survived brain injury after short recovery are lost for the understanding of their health outcomes after short or long period, because they do not come again to the same physician or they forget to say about this important data from their history. Perspective success requires having data on victims' outcomes in the long term. 


\section{Conclusion}

One year after the trafic accidents and surviving traumatic brain injuries (TBIs), victims may still be experiencing multiple problems in terms of not only physical health but also of mental health, social life, and environment. Poor outcome may be predicted from both accident-related factors and socioeconomic fragility. The TBI remain an important public health problem in most industrial developed and especially in developing countries like postwar Bosnia and Herzegovina is especially among young adults. This may also result in temporary or permanent disability. To ensure that patients with trauma and sequel associated with TBIs during road accidents are able to return to previous levels of functioning, it is necessary to make careful observation and taking history from witnesses of an accident not only from the injured person. The TBIs are important healh public problem and the hospital must establish a perfect managemet in these patients for avoid Mental Changes of Commotio Cerebri. All that in order for proper diagnose and proper therapy approach to the patient and needed occupational rehabilitation and resocialization as well as getting proper compensation for the level of mental health impairs.

\section{Acknowledgement}

We are gratitude to Muhammad Hasanovic, for his contribution in preparing this manuscript.

\section{Conflicts of interest}

The authors of the manuscript of reference state that there is no conflict of interest related to the article.

\section{References}

1. Nhac-Vu HT, Hours M, Chossegros L, et al. Prognosis of outcome in adult survivors of road accidents in France: one-year follow-Up in the ESPARR cohort. Traffic Inj Prev. 2014;15(2):138-147.

2. Bener A, Rahman YS, Mitra B, et al. Incidence and severity of head and neck injuries in victims of road traffic craches: In an economically developed country. Int Emerg Nurs. 2009;17(1):52-59.

3. Saatman KE, Duhaime AC, Bullock R, et al. Classification of traumatic brain injury for targeted therapies. J Neurotrauma. 2008;25(7):719-738.

4. Maas AI, Stocchetti N, Bullock R. Moderate and severe traumatic brain injury in adults. Lancet Neurol. 2008;7(8):728-741.

5. Blissitt PA. Care of the critically ill patient with penetrating head injury. Crit Care Nurs Clin North Am. 2006;18(3):321-332.

6. Hannay HJ, Howieson DB, Loring DW, Fischer JS, Lezak MD (2004) Neuropsychological Assessment. In: Lezak MD, Howieson DB and Loring DW (Eds.), Neuropathology for neuropsychologists. (4th edn), Oxford University Press, USA, pp. 158-162.
7. Valadka AB (2004) Injury to the cranium. In: Moore EJ, Feliciano DV, Mattox KL (Eds.), Trauma. (5th edn), McGraw-Hill, New York, USA, pp. 385-406.

8. http:/www.icd10data.com/ICD10CM/Codes/S00-T88/S00-S09/S06/ S06.2-Hayden MG, Jandial R, Duenas HA, Mahajan R, Levy M (2007) Pediatric concussions in sports: a simple and rapid assessment tool for concussive injury in children and adults. Child's Nervous System 23(4): $431-435$.

9. McCrory P, Meeuwisse W, Johnston K, Dvorak J, Aubry M, et al. (2009) Consecuences statement on concussion in sport: the 3rd International Conference on Concussion in Sport held in Zurich. November 2008. J Athl Train 44(4): 434-448.

10. Anderson T, Heitger M, Macleod AD (2006) Concussion and mild head injury. Practical Neurology 6(6): 342-357.

11. Cassidy JD, Carroll LJ, Peloso PM, et al. Incidence, risk factors and prevention of mild traumatic brain injury: results of the who collaborating centre task force on mild traumatic brain injury. Journal of Rehabilitation Medicine. 2004;36(43):28-60.

12. Riggio S, Wong M. Neurobehavioral sequelae of traumatic brain injury. Mount Sinai Journal of Medicine. 2009;76(2):163-172.

13. Hours M, Chossegros L, Charnay P, et al. Outcomes one year after a road accident: Results from the ESPARR cohort. Accid Anal Prev. 2013;50:92-102.

14. Congeni J. Management of the adolescent concussion victim. Adolesc Med State art Rev. 2009;20(1):41-56.

15. Delaney JS, Abuzeyad F, Correa JA, et al. Recognition and characteristics of concussions in the emergency department population. J Emerg Med. 2005;29(2):189-197.

16. McHugh T, Laforce R Jr, Gallagher P, et al. Natural history of the longterm cognitive, affective, and psychical sequelae of mild traumatic brain injury. Brain Cogn. 2006;60(2): 209-211.

17. Avdibegovic E, Hasanovic M, Selimbasic Z, et al. Mental health care of psychotraumatized persons in post-war Bosnia and Herzegovinaexperiences from Tuzla Canton. Psychiatr Danub. 2008;20(4):474-484.

18. Hasanovic M, Herenda S. Post traumatic stress disorder, depression and anxiety among family medicine residents after 1992-95 war in Bosnia and Herzegovina. Psychiatr Danub. 2008;20(3): 277-285.

19. Hasanovic M, Sinanovic O, Pajevic I, et al. Post-war mental health promotion in Bosnia-Herzegovina. Psychiatr Danub. 2006;18(1-2):7478. 